\title{
Successful science without miracles
}

ILKKa NiINILUOTO

\begin{abstract}
Science is highly successful in making empirical predictions and guiding our practical actions. This paper defends the so-called 'ultimate argument for scientific realism' by claiming that this empirical and pragmatic success of scientific theories would be a miracle unless they are true or truthlike. This argument is abductive in Charles Peirce's sense, as it appeals to inference to the best explanation.
\end{abstract}

Keywords: abduction, explanation, fallibilism, inference to the best explanation, scientific realism, truthlikeness

It is generally agreed that science is highly successful in making empirical predictions and guiding our practical actions. The so-called 'ultimate argument for scientific realism' claims that this empirical and pragmatic success of scientific theories would be a miracle unless they are true. This argument is abductive in Peirce's sense, as it appeals to inference to the best explanation. This paper considers the idea that abductive inference can be reformulated by taking its conclusion to concern the truthlikeness of a hypothetical theory on the basis of its success in explanation and prediction. The strength of such a fallible argument is measured by the estimated verisimilitude of its conclusion given the premises.

\section{Critical Scientific Realism}

Scientific realism as a philosophical view has (i) ontological, (ii) semantical, (iii) epistemological, (iv) theoretical, and (v) methodological aspects (see [16], [29]). It holds that (i) at least part of reality is ontologically independent of human mind and culture. It takes (ii) truth to involve a non-epistemic relation between language and reality. It claims that (iii) knowledge about mind-independent 
(as well as mind-dependent) reality is possible, and that (iv) the best and deepest part of such knowledge is provided by empirically testable scientific theories. An important aim of science is (v) to find true and informative theories which postulate non-observable entities to explain observable phenomena.

Critical scientific realism can be distinguished from metaphysical or naive forms of realism by the principle of fallibilism: all factual human knowledge is uncertain or corrigible. Even the best results of science may be false, but still they may be probable, truthlike or approximately true.

Critical scientific realists have argued - following Charles S. Peirce [27], pace opponents like W.V.O. Quine and Larry Laudan (see [10]) - that it indeed makes sense to say that one hypothetical (even false) theory is 'closer to the truth' than another theory. By the same token, it is meaningful to state that a sequence of theories 'approaches to the truth', even when the final limit is not reached. Since 1974, after Karl Popper's 1960 attempt to define verisimilitude turned out to fail, the notion of similarity between states of affairs has been employed to give a precise definition of truthlikeness for scientific statements (see [15], [8]). The degree of truthlikeness $\operatorname{Tr}(\mathrm{H}$, $\mathrm{C}^{*}$ ) of a theory $\mathrm{H}$ is defined relative to a chosen target $\mathrm{C}^{*}$, where $\mathrm{C}^{*}$ is the complete truth expressible in a given conceptual framework. $\operatorname{Tr}\left(\mathrm{H}, \mathrm{C}^{*}\right)$ has its maximum value 1 when $\mathrm{H}$ is identical with $\mathrm{C}^{*}$. Such objective but usually unknown degrees of truthlikeness can be estimated by the expected degree of truthlikeness $\operatorname{ver}(\mathrm{H} / \mathrm{E})$ of $\mathrm{H}$ given available evidence $\mathrm{E}$ (see [15, p. 269]). This measure is an epistemic indicator of objective truthlikeness in the same sense as posterior probability $\mathrm{P}(\mathrm{H} / \mathrm{E})$ of $\mathrm{H}$ given $\mathrm{E}$ is an empirical indicator of the truth of $\mathrm{H}$. For a logical truth $\mathrm{H}$, we have $\mathrm{P}(\mathrm{H} / \mathrm{E})$ $=1$ but $\operatorname{ver}(\mathrm{H} / \mathrm{E})<1$, since $\mathrm{H}$ is not informative. On the other hand, $\operatorname{ver}(\mathrm{H} / \mathrm{E})$ may be non-zero, and even high, when $\mathrm{P}(\mathrm{H} / \mathrm{E})=$ 0 . Thus, while ver involves epistemic probabilities, it is not identical with posterior probability. Given ideal conditions about the correctness and completeness of evidence $\mathrm{E}$, it can be shown that $\operatorname{ver}(\mathrm{H} / \mathrm{E})$ approaches the real degree of truthlikeness $\operatorname{Tr}\left(\mathrm{H}, \mathrm{C}^{*}\right)$ of $\mathrm{H}$ (see [21], [25]). 
The notion of truthlikeness does not replace the objective concept of truth, but rather presupposes the correspondence theory of truth as explicated in Tarski's model-theoretic definition (see [16]). By combining the goals of truth and information, it helps the scientific realist to define scientific progress as theory-change with increasing truthlikeness (see [14]).

Laudan's ([10]) 'pessimistic meta-induction' is based on the premise that many theories in the history of science have been nonreferring and false but yet to some extent empirically successful. By induction, one might infer that this is the fate of our current and future theories as well. However, instead of simply concluding that future theories are false, the realist can argue that in typical cases the successor theory is more truthlike than its predecessor. For example, even though many scientific theories contain idealizations, which are known to be false, the powerful method of 'concretization' helps to remove such assumptions and thereby lead us toward the truth (see [8], [20]). This comparative and dynamic picture of progressive science evades the pessimistic conclusion that all present and future theories are far from the truth.

\section{Abduction and the No Miracle Argument}

In his fallibilist analysis of inference, Peirce argued that science uses, besides deduction, also two ampliative forms of reasoning: induction and abduction. Abduction is reasoning from effects to causes, or from observational data to hypothetical explanatory theories:

(1) The surprising fact $\mathrm{E}$ is observed;

But if $\mathrm{H}$ were true, $\mathrm{E}$ would be a matter of course.

Hence, there is reason to suspect that $\mathrm{H}$ is true.

[27, 5.189]. Against Comte's positivism, Peirce claimed that abduction frequently supposes 'something which it would be impossible for us to observe directly' [27, 2.640].

Peirce insisted that abduction or 'inference to an explanation' has a significant role in science. Often this role has been interpreted as the heuristic function of the discovery of new theories (N. R. Hanson), or alternatively as the motive for suggesting or pursuing testworthy hypotheses. Peirce further pointed out that in sci- 
ence the abductive step is followed by severe observational and empirical tests of the deductive or probable consequences the hypothesis [27, 2.634]. The examples of abduction range from compelling everyday observations to the adoption of theoretical hypotheses in science by virtue of their explanatory and predictive power. In these cases, it appears that sometimes abductive arguments can serve in providing a fallible justification of a hypothesis. Along these lines, Peirce's schema (1) has been interpreted by Gilbert Harman as inference to the best explanation (IBE).

For a critical realist, it is interesting to study the idea that abductive inference (1) can be reformulated by taking its conclusion to concern the truthlikeness of a hypothetical theory on the basis of its success in explanation and prediction (see [7], [18], [19]). This modification of abduction is also relevant to what Alan Musgrave [13] calls the 'ultimate argument for scientific realism'. After the 1950s, when scientific realism became a tenable position after the dominance of empiricism and instrumentalism, several philosophers of science (among them Jack Smart, Hilary Putnam, Grower Maxwell, and Richard Boyd) have defended realism as the best hypothesis which explains the practical (empirical and pragmatic) success of science. The ability of scientific theories to explain surprising phenomena and to yield correct empirical predictions and effective rules of action would be a 'cosmic coincidence' or a 'miracle' unless they refer to real things and are true or at least approximately true or truthlike (see [29], [30]). It is clear that the form of this 'no miracle argument for scientific realism' (NMA) is abductive (see [14, p. 51]).

In his well-known 'confutation of scientific realism', Laudan [10] demanded the realists to show that there is an 'upward path', or an epistemic warrant, from the empirical success of science to the approximate truth of theories - and then a 'downward path' from approximate truth to empirical success. In this paper, I restrict my remarks to the upward path (cf. [14, Ch.7]). For the downward explanation of the empirical success of science by the truth or truthlikeness of theories, and for arguments against alternative putative explanations (cf. [6], [33]), see [16, pp. 192-198]. Theo Kuipers [8] also gives a reply to Laudan by his 'downward' Success Theorem and 'upward' Rule of Success. 
Both Laudan's challenge and the no miracle argument as a reply to this challenge presuppose a minimal realist framework where it makes sense to assign truth values to scientific statements (including theoretical postulates and laws). Besides semantic realists, this framework is accepted by such methodological and epistemological anti-realists who think that the truth of theories is an irrelevant [33] or 'utopian' aim [10] which 'exceeds our grasp' [32]. If successful, the no miracle argument is also relevant to those semantic antirealists and instrumentalists whose inclination to treat theories as schemata without truth values is motivated by their belief about the inaccessibility of theoretical truth.

\section{The Justification of Abduction}

The idea about the justification of abduction has been understood in three different senses. The first is Peirce's own account of truthfrequency, later followed by many frequentist theories of probability and statistics in the 20th century (cf. [3]). The second approach is the qualitative theory of confirmation (cf. [31]). The third approach is the Bayesian theory of inference in terms of epistemic probabilities (see [17]).

Assume that an epistemic probability measure $\mathrm{P}$ is available for the scientific language, and define confirmation by the Positive Relevance criterion: E confirms $\mathrm{H}$ if and only if $\mathrm{P}(\mathrm{H} / \mathrm{E})>\mathrm{P}(\mathrm{H})$. Then, by Bayes's Theorem,

(2) If $\mathrm{H}$ logically entails $\mathrm{E}$, and if $\mathrm{P}(\mathrm{H})>0$ and $\mathrm{P}(\mathrm{E})<1$, then $\mathrm{P}(\mathrm{H} / \mathrm{E})>\mathrm{P}(\mathrm{H})$

This result is the basic principle of the hypothetico-deductive (HD) method in science. More generally, as positive relevance is a symmetric relation, it is sufficient for the confirmation of $\mathrm{H}$ by $\mathrm{E}$ that $\mathrm{H}$ is positively relevant to $\mathrm{E}$. If inductive explanation is defined by the positive relevance condition, i.e., by requiring that $\mathrm{P}(\mathrm{E} / \mathrm{H})>$ $\mathrm{P}(\mathrm{E})$ (see [26], [5]), then we have the general result:

(3) If $\mathrm{H}$ deductively or inductively explains $\mathrm{E}$, then $\mathrm{E}$ confirms $\mathrm{H}$.

The same principle holds for empirical predictions as well, so that (2) can be generalized to the hypothetico-inductive (HI) or 
hypothetico-probabilistic (HP) method ([26], [9]). Hence, by (2) and (3), empirical success confirms the truth of a hypothesis.

It is important that in (3) $\mathrm{H}$ may be a theory expressed in theoretical terms beyond the observational language. If degrees of confirmation are measured by the difference between posterior and prior probability, i.e., $\mathrm{P}(\mathrm{H} / \mathrm{E})-\mathrm{P}(\mathrm{H})$, then evidence $\mathrm{E}$ gives strongest support to the minimal explanation $\mathrm{H}$ that is needed to account for E without irrelevant additions (see [19],[21]). Theoretical postulates are typically needed for such a minimal explanation, as theoretical terms can be logically indispensable for inductive systematization of observation statements (see [26]).

The notion of confirmation is still weak in the sense that the same evidence may confirm many alternative rival hypotheses. It is clear that for given evidence $\mathrm{E}$ one can always conceive many false premises from which $\mathrm{E}$ is derivable. A good theoretical explanation should be initially plausible relative other accepted theories, and it should not only account 'locally' for the given E, but it also should be independently testable by new kind of evidence. Indeed, it can be shown that the confirmation of a theory $\mathrm{H}$ increases if it is able to explain in a unified way many independent phenomena (see [23]). But a confirmed hypothesis need not yet be rationally and tentatively acceptable on evidence. A stronger notion of inference is obtained if one of the rival hypotheses is the best explanation of the facts. The strongest justification is obtained if the hypothesis is the only available explanation of the known facts. The Bayesian approach immediately shows that $\mathrm{P}(\mathrm{H} / \mathrm{E})$ may be close to 1 and $\mathrm{P}(\sim \mathrm{H} / \mathrm{E})$ close to 0 , when $\mathrm{H}$ is the only explanation of $\mathrm{E}$. This suggests that abduction, or Inference to the Best Explanation, might be formulated as a rule of acceptance:

(IBE) A hypothesis $\mathrm{H}$ may be inferred from evidence $\mathrm{E}$ when $\mathrm{H}$ is a better explanation of $\mathrm{E}$ than any other rival hypothesis.

Comparison with Peirce's schema (1) suggests the following version of IBE:

(IBE') If hypothesis $\mathrm{H}$ is the best explanation of evidence $\mathrm{E}$, then conclude for the time being that $\mathrm{H}$ is true. 
In analyzing $\mathrm{IBE}^{\prime}$, it is useful to follow Peirce in distinguishing between deductive and inductive-probabilistic explanations (cf. (3)) (see [17]). But one should also allow approximate explanations: $\mathrm{H}$ approximately explains $\mathrm{E}$ when it is possible to derive from hypothesis $\mathrm{H}$ something $\mathrm{E}^{\prime}$ which is close to $\mathrm{E}$. Indeed, the empirical success of scientific theories in explanation and prediction is often approximate in this sense. For example, Newton's theory explains approximately the laws of Kepler and Galileo. However, here the evidence may still indicate that the best hypothesis is truthlike. This principle might be called inference to the best approximate explanation:

(IBAE) If the best available explanation $\mathrm{H}$ of evidence $\mathrm{E}$ is approximate, conclude for the time being that $\mathrm{H}$ is truthlike.

If degrees of truthlikeness are introduced, then there is a natural addition to IBAE: the greater the fit between $\mathrm{H}$ and $\mathrm{E}$, the larger the degree of truthlikeness of $\mathrm{H}$ in the conclusion. (This gives an answer to P. Kyle Stanford's criticism of Jarrett Leplin's account of partial truth in [32, p. 158].)

By combining the ideas in $\mathrm{IBE}^{\prime}$ and IBAE, inference to the best theory can be formulated by the rule

(IBT) If theory $\mathrm{H}$ is the best explanation of evidence $\mathrm{E}$, conclude for the time being that $\mathrm{H}$ is truthlike.

Here the acceptance of $\mathrm{H}$ is understood in the fallibilist sense that $\mathrm{H}$ is taken to be an informative theory close to the truth. In a comparative formulation,

$\left(\mathrm{IBT}^{\mathrm{c}}\right)$ If $\mathrm{H}^{\prime}$ is a better explanation of evidence $\mathrm{E}$ than $\mathrm{H}$, conclude that $\mathrm{H}^{\prime}$ is more truthlike than $\mathrm{H}$.

(See also $[7,8]$.

Many attempts to defend scientific realism by the no miracle argument NMA appeal to forms of abduction which conclude that successful scientific theories are approximately true, without making the notion of approximate truth precise (e.g., Putnam, Psillos). In a general form this argument looks like the following: 
(NMA) Many theories in science are empirically successful.

The truth or truthlikeness of scientific theories is the best explanation of their empirical success.

Hence, conclude that such successful theories are truthlike.

The same argument can be applied to particular scientific theories. The first premise about the success of science is accepted both by realist and anti-realists, even though in particular cases the attribution of success to a specific theory may be non-trivial (e.g., it may be a matter of controversy whether a medicine, treatment or therapy is really causally effective in producing the desired results). As a whole, the argument NMA involves something like the principle IBT, and the conclusion supports the position of critical scientific realism.

A comparative version of NMA can be given as follows:

$\left(\mathrm{NMA}^{\mathrm{c}}\right)$ Theory $\mathrm{H}^{\prime}$ is empirically more successful than its rival $\mathrm{H}$. That $\mathrm{H}^{\prime}$ is more successful than $\mathrm{H}$ can be explained by the assumption that $\mathrm{H}^{\prime}$ is more truthlike than $\mathrm{H}$.

Hence, conclude that $\mathrm{H}^{\prime}$ is more truthlike than $\mathrm{H}$.

To save the no miracle argument NMA against the charges of circularity ([10], [6]) and incoherence ([33]), one needs to defend abduction in the form of IBT or IBT $^{\mathrm{c}}$.

\section{Upward Inference and Expected Truthlikeness}

The probabilistic account of IBE, given by the results (2) and (3), establishes a probabilistic link between explanatory power and truth: posterior probability $\mathrm{P}(\mathrm{H} / \mathrm{E})$ is the rational degree of belief in the truth of $\mathrm{H}$ on the basis of $\mathrm{E}$, and thereby confirmation, i.e., increase of probability by new evidence, means that we rationally become more certain of the truth of $\mathrm{H}$ than before. But a rule of the form IBAE needs a link between approximate explanation and truthlikeness. The notion of probability (at least alone) does not help us, since the approximate explanation of $\mathrm{E}$ by $\mathrm{H}$ allows that $\mathrm{H}$ is inconsistent with $\mathrm{E}$, so that $\mathrm{P}(\mathrm{E} / \mathrm{H})$ and $\mathrm{P}(\mathrm{H} / \mathrm{E})$ are zero. Also for the treatment of IBT, we need a method for assessing the truthlikeness of a theory given empirical evidence. Here the notion of 
expected truthlikeness ver(H/E) can be used as an empirical indicator of truthlikeness.

Expected verisimilitude helps to define a notion of verconfirmation in analogy with positive relevance: $\operatorname{ver}(\mathrm{H} / \mathrm{E})>\operatorname{ver}(\mathrm{H})$ ([5], [21]). Then we have, for example, the following result:

(4) If $\mathrm{H}$ entails $\mathrm{E}$ but $\sim \mathrm{H}$ does not entail $\mathrm{E}$, then $\mathrm{E}$ ver-confirms $\mathrm{H}$.

This conclusion is still weak. It does not exclude the possibility that the 'catch-all' hypothesis $\sim H$ includes 'unconceived alternatives' to $\mathrm{H}$ which also explain E (see [32]; cf. [30]). However, in cases of 'underdetermination' between rival explanations $\mathrm{H}$ and $\mathrm{H}^{\prime}$, which seem to account for the available evidence E equally well, the scientific strategy is to expand the evidence $\mathrm{E}$ with new observations, instruments, and active experiments, so that eventually a difference in the empirical success of $\mathrm{H}$ and $\mathrm{H}^{\prime}$ is revealed. A powerful mathematical theorem, proved by Johann Radon already in 1917 and today applied in various kinds of abductive 'inverse problems', shows under what conditions evidence guarantees the existence of a unique 'backward solution' (see [24]).

Another application of ver is to use expected verisimilitude as a criterion of acceptance. This is in harmony with the suggestion that the strength of IBT is assessed in terms of the expected verisimilitude of its conclusion given the premises. Thus, in order to reply to Laudan's 'upward' challenge, we should investigate whether the following kinds of principles are valid:

(5) If $\mathrm{H}^{\prime}$ is a better approximate explanation of $\mathrm{E}$ than $\mathrm{H}$, then $\operatorname{ver}\left(\mathrm{H}^{\prime} / \mathrm{E}\right)>\operatorname{ver}(\mathrm{H} / \mathrm{E})$.

(6) If $\mathrm{H}$ approximately explains $\mathrm{E}$, then $\operatorname{ver}(\mathrm{H} / \mathrm{E})$ is high.

(7) If $\mathrm{H}$ is the best available explanation of $\mathrm{E}$, then $\operatorname{ver}(\mathrm{H} / \mathrm{E})$ is high.

(Cf. [22].) These results, which can be proved at least in special cases (see [19]), show that explanatory success gives us a rational warrant for making claims about truthlikeness. Thereby the notion 
of expected truthlikeness, explicated by the function ver, provides $a$ fallible link from the empirical success of a theory to its truthlikeness.

Under ideal conditions, where a high value of $\operatorname{ver}(\mathrm{H} / \mathrm{E})$ guarantees that the objective degree of truthlikeness $\operatorname{Tr}\left(\mathrm{H}, \mathrm{C}^{*}\right)$ is also high, results (5)-(7) show that the method of accepting theories with maximal estimated verisimilitude is 'functional for truth approximation' in the sense of Kuipers [8, 9] (cf. [25]).

It is important to emphasize the fallible nature of results like (2), (3), and (5)-(7). The notions of confirmation and expected verisimilitude are historical, relative to the rival theories and evidence available at a given time. Some philosophers have continued Laudan's pessimistic argument, in many cases against formulations of Stathis Psillos [29], by giving historical examples of past theories which had some empirical success, including novel successes in relation to their predecessors, but still are non-referring and false by present lights. Against the claims of 'preservative' or 'localized' realism, such successes may have been based upon theoretical postulates that are discredited today (see [2], [4], [12], [32]). However, critical realists may acknowledge that, for example, relative to the historical situation the caloric theory of heat was well supported by the available evidence. By $\mathrm{NMA}^{\mathrm{c}}$, such theories were progressive in relation to their predecessors. (For the case of phlogiston theory, see [16, pp. 191-192]; for old quantum theory, see [8, pp. 278-288].) The fact that such theories have been replaced by better theories is not a 'Pyrrhic victory' for scientific realism (see [32]), since it supports the realist picture of scientific progress as increasing truthlikeness.

In fact, the measure of expected verisimilitude can be used also for retrospective comparisons, if the evidence $\mathrm{E}$ is taken to include our currently accepted theory $\mathrm{T}$, i.e., the truthlikeness of a past theory $\mathrm{H}$ is estimated by $\operatorname{ver}(\mathrm{H} / \mathrm{E} \& \mathrm{~T})$ (see [14, p. 171]). In a similar way, Jeffrey Barrett [1] has proposed that - assuming that science makes progress toward the truth through the elimination of descriptive error - the 'probable approximate truth' of Newtonian gravitation can be warranted by its 'nesting relations' to the general theory of relativity. 


\section{Conclusion}

Non-scientific explanations of the success of science - e.g. appeal to miracles or God's will - are not satisfactory. Therefore, we may conclude that scientific realism is the only explanation of the empirical success of science. This strong form of IBE justifies the no miracle argument NMA, and thereby gives us the best defence of scientific realism.

\section{References}

[1] Barrett, J. A., Approximate Truth and Descriptive Nesting, Erkenntnis 68:213-224, 2008.

[2] Chang, H., Preservative Realism and Its Discontents: Revisiting Caloric, Philosophy of Science 70:902-912, 2003.

[3] Douven, I., Empirical Equivalence, Explanatory Theories, and the Inference to the Best Theory, in R. Festa, A. Aliseda, and J. Peijnenburg (eds.), Confirmation, Empirical Progress, and Truth Approximation, Amsterdam: Rodopi, 2005, pp. 281-313.

[4] Elsamahi, M., A Critique of Localized Realism, Philosophy of Science 72:1350-1360, 2005.

[5] Festa, R., Bayesian Confirmation, in M. C. Galavotti and A. Pagnini (eds.), Experience, Reality, and Scientific Explanation, Dordrecht: Kluwer, 1999, pp. 55-87.

[6] Fine, A., Unnatural Attitudes: Realist and Instrumentalist Attachments to Science, Mind 95:149-179, 1986.

[7] Kuipers, T., Abduction aiming at Empirical Progress or even Truth Approximation leading to a Challenge for Computational Modelling, Foundations of Science 4:307-323, 1999.

[8] Kuipers, T., From Instrumentalism to Constructive Realism: On Some Relations between Confirmation, Empirical Progress, and Truth Approximation, Dordrecht: Kluwer, 2000.

[9] Kuipers, T., The Hypothetico-Probabilistic (HP)-Method as a Concretization of the HD-Method, in S. Pihlström, P. Raatikainen \& M. Sintonen (eds.), Approaching truth: Essays in honour of Ilkka Niiniluoto, London: College Publications, 2007, pp. 179-207.

[10] Laudan, L., Science and Values, Berkeley and Los Angeles: University of California Press, 1984.

[11] LePlin, J., A Theory's Predictive Success can Warrant Belief in the Unobservable Entities it Postulates, in C. Hitchcock (ed.), Contemporary 
Debates in Philosophy of Science, Oxford: Blackwell, 2004, pp. 117132.

[12] Lyons, T., Scientific Realism and the Stratagema de Divide et Impera, British Journal for the Philosophy of Science 57:537-560, 2006.

[13] Musgrave, A., The Ultimate Argument for Scientific Realism. in R. Nola (ed.), Relativism and Realism in Science, Dordrecht: Kluwer, 1988.

[14] Ninnlluoto, I., Is Science Progressive?, Dordrecht: D. Reidel, 1984.

[15] Niıniluoto, I., Truthlikeness, Dordrecht: D. Reidel, 1987.

[16] Ninnluuto, I., Critical Scientific Realism, Oxford: Oxford University Press, 1999.

[17] Nimiluoto, I., Defending Abduction, Philosophy of Science(Proceedings) 66:436-451, 1999.

[18] Ninnlluoto, I., Truth-seeking by Abduction, in F. Stadler (ed.), Induction and Deduction in the Sciences, Dordrecht: Kluwer, 2004, pp. 5782 .

[19] Ninnluoto, I., Abduction and Truthlikeness. in R. Festa, A. Aliseda, and J. Peijnenburg (eds.), Confirmation, Empirical Progress, and Truth Approximation, Amsterdam: Rodopi, 2005, pp. 255-275.

[20] Ninnlluoto, I., Idealization, Counterfactuals, and Truthlikeness, in J. Brzezinski et al. (eds.), The Courage of Doing Philosophy: Essays Presented to Leszek Nowak, Rodopi: Amsterdam, 2007, pp. 103-122.

[21] Ninnlluoto, I., Evaluation of Theories. in T. Kuipers (ed.), Handbook of Philosophy of Science: General Philosophy of Science - Focal Issues, Amsterdam: Elsevier, 2007, pp. 175-217.

[22] Ninniluoto, I., Abduction and Scientific Realism, in F. Keskin (ed.), The Proceedings of the Twenty-First World Congress of Philosophy, vol. 12. Philosophical Trends in the XXth Century, Ankara: Philosophical Society of Turkey, 2007, pp. 137-142.

[23] Nisniluoto, I., Abduction, Unification, and Bayesian Confirmation: Comment on Schurz, in C. Dermont, L. Keiff, and H. Rückert (eds.), Dialogues, Logic and Other Strange Things, London: College Publications, 2008, pp. 365-370.

[24] Ninnluuoto, I., Abduction, Tomography, and Other Inverse Problems, Studies in History and Philosophy of Science 42:135-139, 2011.

[25] Niıniluoto, I., Revising Beliefs Towards the Truth, Erkenntnis 75:165-181, 2011. 
[26] Ninniluoto, I., and R. Tuomela, Theoretical Concepts and Hypothetico-Inductive Inference, Dordrecht: D. Reidel, 1973.

[27] Peirce, C. S., Collected Papers 1-6, ed. by C. Hartshorne and P. Weiss. Cambridge, MA: Harvard University Press, 1931-35.

[28] Pinlström, S., Raatikainen, P., and Sintonen, M. (eds.), Approaching Truth: Essays in Honor of Ilkka Niiniluoto, London: College Publications, 2007.

[29] Psillos, S., Scientific Realism: How Science Tracks Truth, London: Routledge, 1999.

[30] Psillos, S., Knowing the Structure of Nature: Essays on Realism and Explanation, Houndmills: Palgrave Macmillan, 2009.

[31] Smokler, H., Conflicting Conceptions of Confirmation, The Journal of Philosophy 65:300-312, 1968.

[32] Stanford, P. K., Exceeding Our Grasp: Science, History, and the Problem of Unconceived Alternatives, Oxford: Oxford University Press, 2006.

[33] van Fraassen, B., Laws and Symmetry, Oxford: Oxford University Press, 1989. 